\title{
LIÇÕES PRELIMINARES PARA UMA PERSPECTIVA ALTERNATIVA DE CIDADANIA
}

\author{
PRELIMINARY LESSONS FOR AN ALTERNATIVE \\ PERSPECTIVE OF CITIZENSHIP
}

Mazukyevicz Ramon S. N. Silva

mazukyevicz@hotmail.com

Recebido em: 12/07/2013

Aprovado em: 02/10/2013

SUMÁRIO: 1. Pressupostos para uma análise crítica da cidadania; 2. O paradigma liberal de cidadania; 3. Cidadania e a antítese marxista; 4. Conclusão. Referências.

RESUMO:

$\mathrm{O}$ artigo em questão é parte integrante da pesquisa intitulada "A dimensão cultural da educação em prisões”, realizada em nível de Doutorado junto ao Programa de PósGraduação em Direito da Universidade Federal da Paraíba. Utiliza de uma abordagem metodológica dialética, com base na teoria crítica, com a finalidade de investigar uma concepção alternativa de cidadania em oposição ao paradigma liberal predominante. Analisando seu objeto a partir da tese dos frankfurteanos Adorno e Horkheimer e das idéias marxistas que apontam o caráter limitado da cidadania liberal, o presente texto pretende demonstrar que, se por um lado o modelo de cidadania liberal é positivo na medida em que expande o alcance dos direitos de liberdade, por outro, não se revela como suficiente para a emancipação humana, por estimular a competição entre os homens.

Palavras-Chave

Cidadania; Direitos Humanos; Teoria Crítica.
ABSTRACT

The article in question is part of the research entitled "The cultural dimension of education in prisons", held at Doctorate level by the Graduate Program in Law from the Federal University of Paraíba. Uses a dialectical methodological approach, based on critical theory, in order to investigate an alternative conception of citizenship in opposition to the dominant liberal paradigm. Analyzing your object from the thesis of Adorno and Horkheimer frankfurteanos and Marxist ideas that link the limited nature of liberal citizenship, this article intends to demonstrate that, on the one hand the model of liberal citizenship is positive in that it expands the range rights of freedom, on the other it does not seem like enough for human emancipation, by encouraging competition among men.

\section{Keywords}

Citizenship, Human Rights, Critical Theory. Keywords: Citizenship, Human Rights, Critical Theory. 


\section{PRESSUPOSTOS PARA UMA ANÁLISE CRÍTICA DA CIDADANIA}

Entende-se por teoria crítica toda teoria não reducionista da realidade, ou seja, a realidade, a partir de uma perspectiva crítica se apresenta sempre como um conjunto de novas possibilidades, sendo a tarefa do teórico crítico a adoção de uma postura de indignação e inconformismo perante o que existe, e a indicação dos modelos alternativos disponíveis (SANTOS, 1999, p.1).

Tal como ensinaram Adorno e Horkheimer em sua Dialética do Esclarecimento (2006, p.17), "a superioridade do homem está no saber"; mas não num saber qualquer; não num saber que se rende dogmaticamente ao pragmatismo da atividade científica dos nossos dias, e que funciona como um mero instrumento à disposição da ordem dominante. Ao contrário, a superioridade do homem reside numa perspectiva positiva de esclarecimento ${ }^{1}$, assim entendida aquela que entrelaça racionalidade e realidade social, a que se ocupa da verdade essencial das coisas e não apenas da eficácia dos procedimentos empregados, refutando assim o ato de estacionar em análises superficiais de seu objeto de investigação.

$\mathrm{Na}$ Crítica da Razão Instrumental, publicada originalmente em 1967, Max Horkheimer se propõe a distinguir os diferentes conceitos de racionalidade. Para o filósofo, a razão pode se mostrar de duas maneiras distintas: a primeira, chamada razão subjetiva ou instrumental, diz respeito à capacidade humana de classificar, concluir e deduzir sobre aquilo que lhe é útil, sem se deter ao conteúdo, ou em outras palavras, trata-se de um tipo de racionalidade que se ocupa apenas do funcionamento abstrato do mecanismo pensante, sem reflexão, sem crítica. É, pois, uma razão que se preocupa exclusivamente em adequar os meios aos fins desejáveis, sejam esses fins razoáveis ou não em seu conteúdo. Sob a perspectiva da razão instrumental, algo é racional na medida em que se apresenta como útil, e nada mais. Ela é formal, neutra, abstrata, lógico-matemática (HORKHEIMER, 1973, p.9 11).

Por outro lado, Horkheimer chamou de objetiva a razão que, conhecida desde a antiguidade clássica, não se relaciona a vantagens ou utilidades imediatas, ou seja, a que se apresenta como razoável não por que se orienta por finalidades, mas por ser razoável em si mesma. A racionalidade pensada a partir dessa perspectiva se dedica a refletir sobre a totalidade da ordem social, as relações humanas, a organização da sociedade, a natureza, o cosmo.

\footnotetext{
Segundo Adorno e Horkheimer (2006, p.17), entende-se por esclarecimento o processo histórico e racional de desencantamento do mundo pelo qual o homem vai dissolvendo as explicações mitológicas da realidade e substituindo-as pelo saber, abandonando assim os medos e se colocando na posição de senhores de si.
} 
Platão, em sua $A$ Republica, já organizara sua teoria do conhecimento a partir de uma dimensão objetiva e total da racionalidade. Utilizando da tradicional metáfora da Alegoria da Caverna ${ }^{2}$, o socrático ilustra a existência de dois mundos, um mundo sensorial, aparente e imperfeito - no qual os homens vivem e desenvolvem relações a partir de seus sentidos - e um mundo inteligível, cognoscente e real, acessível apenas mediante o uso de uma racionalidade crítica.

Ocorre que, conforme ensinam Adorno e Horkheimer (2006, p. 17-46), ao longo da história, na sua missão de dominar e controlar a natureza e dissolver o mundo das superstições e das mitologias, a faculdade objetiva do pensar foi se instrumentalizando, e assim, em busca de uma objetividade cada vez maior, hipertrofiou-se em relação ao tratamento dos meios e esqueceu a reflexão substancial acerca dos fins. A razão se transformou então em abstração, em procedimento, em formalismo, em técnica, e deixou de ser uma forma de acesso a conhecimentos nucleares e passou a servir de instrumento para a perda da autonomia do indivíduo, de dominação, de poder, de exploração.

\begin{abstract}
Tendo cedido em sua autonomia, a razão tornou-se um instrumento. No aspecto formalista da razão subjetiva, sublinhada pelo positivismo, enfatiza-se a sua não referência a um conteúdo objetivo; em seu aspecto instrumental, sublinhado pelo pragmatismo, enfatiza-se a sua submissão a conteúdos heterônomos. A razão tornou-se algo inteiramente aproveitado no processo social. Seu valor operacional, seu papel de domínio dos homens e da natureza tornou-se o único critério para avaliá-la (HORKHEIMER, 2007, p.29)
\end{abstract}

Como narrou Platão em sua alegoria acerca do homem que se desprendera do mundo das sombras, "se alguém o forçasse a olhar para a própria luz, doer-lhe-iam os olhos e voltar-se-ia, para buscar refúgio junto dos objetos para os quais podia olhar", de maneira que, o processo de instrumentalização da razão é naturalizador do homem, e assim, uma reversão no uso da razão segundo a lógica atual é tarefa densa e árdua.

Daí que, o desafio que se apresenta ao pesquisador comprometido com a verdade é o da reconstrução do caráter objetivo da racionalidade, numa lógica ou movimento contrários a formalização do pensamento que se utilize de um método capaz de considerar os fenômenos investigados em sua totalidade, na busca por sua essência. Segundo o filósofo grego, o método dialético seria o único capaz de proceder a destruição das hipóteses no sentido das descobertas autênticas (PLATÃO, 2009, p.230).

2 Diálogo narrado no Livro VII da República de Platão, entre Sócrates e Glauco, este último irmão de Platão em que o filósofo descreve uma caverna escura, por onde entraria apenas um feixe de luz, que refletiria as sombras dos objetos e pessoas que transitavam do lado externo da caverna, para homens acorrentados no interior da caverna desde a infância, ilustrando assim a escuridão que aprisiona os homens que se utilizam apenas de suas impressões sensoriais, de maneira que apenas com o uso da razão tais homens poderiam descobrir a luz da verdade. 
Na Lógica Formal e Lógica Dialética de Henri Lefebvre (1991, p.80), em sendo o conhecimento prático, social e histórico, não pode jamais se prender a uma investigação aristotélica formal, ou seja, que deixa de lado qualquer necessidade de análise de conteúdo ocupando-se apenas dos contornos do pensamento puro ou das regras gerais de coerência do pensamento consigo mesmo, mas ao contrário, se a realidade de apresenta como móvel, múltipla, diversa, contraditória, lançá-la numa racionalidade formalista é renegá-la a um campo de problemas insolúveis.

Para Lefebvre (1991, p.83), "a forma é sempre forma de um conteúdo", e sendo assim, forma e conteúdo se apresentam necessariamente num movimento incessante. Se por um lado a lógica formal tem um alcance apenas relativo e limitado, a lógica do conteúdo é concreta, e considerando que o conhecimento verdadeiro é feito das interações entre forma e conteúdo, sujeito e objeto, ou seja, de elementos opostos, a análise dessas interações é chamada de dialética, e a lógica do conteúdo é a lógica dialética.

Em Dialética do Concreto, Karel Kosik apresenta definições acerca do conceito de crítica e do método dialético de investigação, como oposição à racionalidade/ lógica instrumental e utilitária. Para o autor, o conhecimento da realidade pode ser obtido a partir do estudo das representações (forma) ou da essência das coisas (conteúdo), sendo que a dialética lida justamente com essa distinção, daí por que se apresenta como um algo da práxis humana, e não apenas do mundo das ideias. A realidade não se apresenta ao homem, então, como objeto teórico isolado do contexto prático. Por outro lado, a realidade da forma, como ela se manifesta, nem sempre coincide com o conceito da coisa em si, ao que o autor chama de aspecto fenomênico da realidade, de maneira que se as representações da realidade são úteis apenas numa dimensão superficial, pois não servem para a compreensão essencial dos objetos investigados.

Em clara referência aos conceitos de Marx, Kosik (2011, p.13-25) discute que esse mundo de representações só é útil aqueles homens que dominam as condições sociais, que estão no topo da sociedade classista, uma vez que se a maioria dos homens desconhecem a compreensão real das coisas, entendem sua realidade como imutável e normal, ou seja, a partir de uma consciência ingênua e não crítica.

Contudo, alerta o autor que a essência da coisa não se afasta por completo de suas representações, pois se assim fosse, o mundo dos fenômenos seria facilmente notado como irreal, e o mundo essencial seria inalcançável, assim, o chamado mundo da pseudoconcreticidade se confunde com o mundo da coisa em si. Enquanto o mundo da pseudoconcreticidade se apresenta ao homem de maneira imediata, o mundo essencial só é descoberto mediante a investigação crítica, e por isso mesmo dialética. 
Por tudo isso, considerando que as reflexões contemporâneas sobre a noção de cidadania têm evidenciado uma vinculação com a perspectiva liberal do cidadão como um detentor de direitos e obrigações oponíveis ao Estado e aos demais sujeitos, predominando assim uma dimensão individualista e concorrente; e no mais, considerando que a afirmação do paradigma liberal de cidadania não foi suficiente para erradicar problemas históricos relativos à condição humana indigna, mas ao contrário, acabou por contribuir para a reificação do ser, o presente texto, utilizando-se de uma abordagem dialética e crítica, se propõe a apresentar elementos preliminares para uma análise alternativa da cidadania, recorrendo, para tanto, à perspectiva marxista de cidadania como antítese à concepção predominante.

\section{O PARADGIMA LIBERAL DE CIDADANIA}

O polites Grego da polis, e o civis Romano da res publica, acabaram por definir uma forma única de associação humana que viria a ser transmitida como ideal de cidadania para o ocidente, sendo que, o diálogo interminável entre essas duas concepções torna-se determinante para o entendimento da concepção de cidadania no pensamento político contemporâneo (POCOCK, 1995, p.29).

Em seu texto The ideal of citrenship since classical times, de 1995, o citado historiador inglês explica que na concepção aristotélica, cada cidadão pertencia a duas ordens de existência, um domínio privado - das ações dos homens sobre as coisas (oikos) - e um domínio público, no qual as pessoas interagiam entre si (polis), de maneira que somente mediante a emancipação de seu espaço privado para o espaço político, o cidadão alcançaria seu bem maior.

Por outro lado, na concepção romana o enfoque de atenções passou do cidadão como ser político para o cidadão como ser legal, pois, enquanto para os gregos as coisas se restringiam ao oikos e somente com uma vida política ativa o cidadão viveria em virtude, em Roma, as ações humanas teriam como objeto as coisas, ou ainda, a manutenção de suas posses, e como a relação do homem com as cosisas estava regulada pela lei, a cidadania traria consigo um conjunto de direitos possessórios, assumindo assim um status não político, mas legal. O status de cidadão deixaria então de relacionar-se com a participação ativa no espaço político, para designar o pertencimento a uma comunidade de direito condicionado à propriedade 3 (POCOCK, 1995, 36-38).

3 Conforme ensina PINSKY (2008, p. 44-49), esse caráter legal relacionado à propriedade, da cidadania romana, só foi verificado a partir da expansão do império, no século I a.C, como resultado de uma poderosa política de assimilação a partir da qual a civitas romana era conferida aos povos vencidos. Antes, a cidadania se sujeitava aos critérios de sangue e territorialidade, assim, ser cidadão era acima de tudo ser livre, status esse alcançado exclusivamente por descendência familiar e nascimento no território. 
Pocock $(1995$, p.43) ainda chama atenção para o fato de que essa fórmula de cidadania legal, em que os homens se isolam em suas individualidades por viverem separados por suas coisas, tornar-se-ia a principal referência para a formulação do liberalismo moderno.

A partir daí, ensina Comparato (1993, p.4), que com o desaparecimento das civilizações Greco-romanas, o mundo ocidental atravessou vários séculos de supressão da cidadania, em que o status de cidadão "foi substituído por um complexo de relações hierárquicas de dominação privada", que culminou no estágio de centralização do poder político do regime absolutista, sendo contra este regime que se forjou o espaço de liberdades individuais do mundo político moderno.

O primeiro elemento característico da cidadania liberal forjada na modernidade é a ideia de individualismo e titularidade de direitos em contraposição ao poder soberano. Atribui-se a Thomas Hobbes a condição de fundador da tradição moderna dos direitos individuais, num contexto histórico e conceitual que se evidenciou na Europa a partir do século XVI - no qual o homem substituiu Deus como o fundamento das explicações do mundo e o direito natural objetivo da Antiguidade foi substituído pelo direito subjetivo como faculdade humana (DOUZINAS, 2009, p.83) - e que pode ser ilustrado pela seguinte passagem, extraída do Leviatã, de 1651:

O direito natural, que os autores geralmente chamam jus naturale, é a liberdade que cada um possui de usar seu próprio poder, da maneira que quiser, para a preservação de sua própria natureza, ou seja, de sua vida. Consequentemente de fazer tudo aquilo que seu próprio julgamento e razão the indiquem como meios adequados a esse fim. Conforme o significado próprio da palavra, por liberdade entende-se a ausência de impedimentos externos, que muitas vezes tiram parte do poder que cada um tem de fazer o que quer, mas não podem proibir a que use o poder que lhe resta, conforme o que seu julgamento e razão lhe ditarem (HOBBES, 2006, p.101).

A razão, livre das explicações metafísicas de outrora implicaria então no reconhecimento do livre arbítrio humano, na autonomia dos desejos individuais, na posse de direitos limitados apenas pelos direitos dos outros, assim, o desejo de autopreservação, para Hobbes, faria com que os homens abandonassem sua liberdade originária em troca da segurança das leis de um Soberano, de poderes irrestritos e absolutos; amadurecem então as ideias de individualismo, Estado de natureza, e Estado soberano, que se constituiriam como o alicerce da filosofia política liberal (DOUZINAS, 2009, p.83-91).

A tradição liberal viria então a se opor ao absolutismo soberano, a partir de uma concepção negativa de Estado como mal necessário que deveria ser limitado e controlado para não interferir na esfera privada dos cidadãos. Explica Berlin (1981, p.136) que a liberdade nessa dimensão é a área em que um homem pode agir sem 
interferências externas, pois "quanto mais ampla a área de não interferência, mas ampla minha liberdade".

John Locke, por sua vez, que se utilizou das bases conceituais trabalhadas por Hobbes - e seus escritos costumam ser apresentados como o marco inicial do liberalismo moderno - ensinou que o Estado de Natureza é repleto de perigos, e o único meio de que dispõe o homem para sair dessa condição é buscar a felicidade mediante o estabelecimento de uma sociedade civil, cujo principal propósito é a proteção da propriedade, sob a garantia das leis. Para Locke, o direito natural da propriedade tem seu fundamento na posse que cada homem tem de seu corpo, de suas habilidades, de seu trabalho e de sua produção (LOCKE, 2006).

Douzinas (2009, p.97) explica que as contribuições de Locke para a análise da propriedade produziu efeitos revolucionários, pois, a partir daí, o indivíduo se coloca no centro do mundo moral e político por que "cria e possui valor por meio de seus próprios esforços", de maneira que autonomia, independência e criatividade tornam-se símbolo da realização humana, e o poder livre de adquirir torna-se símbolo de auto-realização e dignidade. Ressurge assim, um segundo elemento característico da cidadania liberal, a ideia de cidadão como proprietário, tal como presente na tradição dos romanos.

Do clássico Sobre a Liberdade de John Stuart Mill, extrai-se um terceiro elemento para a caracterização da cidadania liberal, o chamado princípio do dano. Para o autor, a única liberdade é a liberdade sem reservas, absoluta, composta pelo domínio íntimo da consciência, a liberdade de dispor do próprio plano de vida sem a interferência dos semelhantes, e a liberdade de se unir para qualquer propósito que não envolva dano - e a única finalidade justificativa da interferência dos homens na liberdade de ação de outrem, é a intencionalidade de impedir que uma vontade provoque dano em outra (MILL, 2006, p.34). A partir do princípio do dano, evidencia-se que a liberdade e a supremacia do individualismo não seriam oponíveis apenas em face da organização política centralizada, mas também em relação aos demais cidadãos, numa espécie de concorrência mútua para o exercício das liberdades.

Hayek (1981, p.47-63) resume da seguinte maneira os princípios de uma ordem liberal: primeiro, a abstração da ordem espontânea funciona como maximização da ordem ao mesmo tempo em que funciona como limite concreto dessa ordem, ou seja, o poder pode alguma coisa, mas não pode tudo; segundo, a ordem espontânea não tem apenas um objetivo específico (poder central), mas objetivos recíprocos que se somam para o beneficio comum, possibilitando assim a coexistência harmônica de todos independentemente dos objetivos de grupos isolados; terceiro, a ordem espontânea não é apenas econômica no sentido de uma troca de recursos, mas se torna econômica no sentido de admitir que todos tenham oportunidade de 
buscar seus objetivos concretos independentemente de objetivos impostos por uma opinião específica, ao que se dá o nome de catalaxia; quarto, o liberalismo depende de regras formais e abstratas, de caráter proibitivo/negativo, que garantam a todos gozar de seu patrimônio individual; quinto, a noção de justiça no liberalismo é algo que se deve buscar nas ações humanas e não na vontade única do legislador.

Impende destacar que, conforme ensina Hayek (1981, p.48) o liberalismo clássico seria resultante não só dessa construção teórica, mas de uma tentativa de generalizar a ordem espontânea dos indivíduos em oposição às limitações impostas pelos poderes centrais do Soberano, assim, para o autor, a ideia central de liberalismo é a da existência de regras universais de conduta justa, que protejam o domínio privado dos indivíduos - propriedade privada - contra os arranjos deliberados, pois, somente numa ordem espontânea seria possível proporcionar a melhor oportunidade para qualquer um de deus membros buscar a consecução de seus objetivos mediante a utilização de seus próprios meios.

Ocorre que nem só de conceitos se compõe a genealogia da cidadania liberal. Com efeito, as ideias acima expostas surgiram entre os séculos XVI e XVIII, num período de notória ebulição social, marcado pela ascensão da burguesia e seus processos de reivindicação de maior representação política frente à nobreza e ao clero. Tais ideias viriam a fornecer as justificativas ideológicas dos movimentos revolucionários que levariam à definitiva constituição do mundo moderno.

Dentre estes movimentos, destacam-se os que culminaram com a Bill of Rights inglesa, de 1689; a Declaração de Direitos do Estado da Virgínia, de 1777 e que foi a base da Declaração da Independência dos Estados Unidos da América em 1791; e a Declaração dos Direitos do Homem e do Cidadão da Revolução Francesa de 1789. Tais declarações de direitos foram responsáveis pela construção da pretensão de mundialização do binômio individualismo/liberdade e da passagem dos direitos naturais para os direitos humanos, que teriam sua representação máxima na Declaração Universal dos Direitos Humanos da ONU, de 1948 (DOUZINAS, 2009, p.99).

Embora a noção dos direitos humanos como valores morais historicamente construídos não se confunda com a de cidadania, é forçoso reconhecer que o processo de afirmação daqueles, mantém estreita relação com a ampliação da filosofia política liberal. Nesse sentido, ensina Bobbio em sua Era dos Direitos que a partir da Declaração Universal dos Direitos Humanos de 1948, os direitos se desenvolveram evidenciando três tendências (BOBBIO, 2004): universalização, a partir do qual os princípios de direitos humanos foram alcançando quase a totalidade das nações do mundo; multiplicação, pelo qual cada vez mais direitos foram sendo incorporados ao repositório dos direitos humanos; e especificação, fenômeno que caracterizou-se pela inclusão de um número cada vez maior de indivíduos na qualidade de sujeitos de direitos humanos. 
Das lições do cientista político italiano é possível inferir que, no período que compreende a chamada "Era dos Direitos", a concepção de cidadania liberal alcançou contornos de universalidade, ao passo em que os direitos de liberdade foram sendo, aos poucos, distribuídos a uma quantidade mais ampla de pessoas e grupos, disseminando assim o status legal da cidadania. Também se revestiu de um caráter abstrato, na medida em que se multiplicou como corolário do reconhecimento de um valor individual comum a todos os homens.

A fórmula atual da cidadania liberal pode ser bem condensada a partir da concepção clássica que T.H. Marshall apresentou em sua obra Cidadania e Classe Social, de 1949. Para o autor, a cidadania seria um status conferido aos homens comprometidos com sua "deliberação independente", ou seja, sua capacidade de racionalmente, desenvolver suas ações no espaço público em busca de suas necessidades individuais, e por isso, tais homens seriam detentores de um rol de direitos, que Marshall, a partir de uma análise histórica da sociedade inglesa, dividiu em direitos civis, relacionados a não interferência externa no domínio privado; direitos políticos, relacionados à participação ativa na administração do poder; e direitos sociais, relacionados às garantias mínimas para a concorrência igualitária no espaço público (MARSHALL, 1967). Distribuição de direitos aos homens subjetivamente e materialmente proprietários, eis a tese liberal de cidadania.

\section{CIDADANIA E A ANTÍTESE MARXISTA}

O marxismo propriamente dito, tomado enquanto teoria crítica, surge por volta de 1843, quando na Crítica da filosofia do direito público de Hegel, Marx se propõe aos estudos de uma lógica real em oposição a lógica abstrata hegeliana, e passa a explicar a realidade a partir de uma concepção materialista, segundo a qual as ideias se explicam a partir da realidade, refutando assim o idealismo (ATIENZA, 1982, p.40).

Na Ideologia Alemã, de 1946, junto com Engels, Marx (1982, p.6) afirmou que "não é a consciência que determina a vida, mas sim a vida que determina a consciência", ou seja, o que são e o que fazem os indivíduos dependem das condições materiais que determinam a produção e a vontade daqueles (ATIENZA, 1982, p.51).

O filósofo do direito espanhol explica que, não se identifica ao longo da obra de Marx uma teoria própria dos direitos humanos, assim, a crítica marxista aos direitos liberais deve ser compreendida em sua totalidade. Longe de descartar a ideia de direitos humanos, a perspectiva de Marx e seus seguidores era no sentido de que o uso preciso do termo haveria de compreender tais direitos como aqueles que dizem respeito exclusivamente a uma liberdade e igualdade formais entre os 
homens, e que só se produzem num certo momento histórico, como metarrelato do sistema social burguês na modernidade (ATIENZA, 1982, p.2).

Por liberdade e igualdade formais deve-se entender o caráter abstrato e ilusório dos direitos - sobretudo do direito à propriedade - que desconectados das condições materiais de sua implementação, "reduz tudo ao homem, isto é, ao indivíduo, do qual retira toda determinidade" (MARX, 2004, p.149). Como traduz Meszáros (2008, p.159), a proclamação formal de um direito a propriedade comum a todos os homens, que se operou na passagem histórica do feudalismo ao capitalismo, implicou numa igualdade abstrata do direito de aquisição, e "culminou em uma contradição radical, visto que implicou necessariamente a exclusão de todos os outros da posse efetiva, restrita a um só indivíduo”. Em outras palavras, em sendo os homens livres e iguais em direitos formalmente considerados, o fato de não Ter ou Possuir é atribuído exclusivamente à incapacidade individual ou subjetiva de cada um.

Douzinas (2009, p.109), em seu O fim dos direitos bumanos, explica que os direitos da tradição liberal são direitos de um homem abstrato, vazio, inexistente no plano material; tanto que, a Declaração de Direitos da Revolução Francesa e a Declaração Universal dos Direitos Humanos de 1948 afirmam que "todos os homens nascem iguais em direitos e em dignidade", contudo, basta introduzir a dimensão empírica ou histórica na análise dessa natureza humana abstrata para constatar que a desigualdade entre os homens é muito mais evidente, e a igualdade natural é corporificada no homem, branco, e proprietário.

A universalidade e a abstração dos direitos das declarações constroem o poder de um homem concreto, que tem na propriedade privada o fundamento de todos os demais direitos; tal como Rousseau (1996, p.26) afirmou no século XVIII:

É certo que o direito à propriedade é o mais sagrado de todos os direitos da cidadania, e sob certos aspectos ainda mais importantes do que a própria liberdade, ou porque afeta mais de perto a preservação da vida ou porque, como a propriedade é mais facilmente usurpada e mais difícil de defender do que a vida, a Lei deveria dar maior atenção ao que pode ser mais facilmente tomado.

Com efeito, as declarações dos direitos liberais, ao selecionar o homem proprietário como modelo de homem abstrato, afirmavam a inclusão e realizaram a exclusão concomitantemente, de maneira que, a Declaração de Direitos norteamericana não considerava os escravos enquanto homens livres e titulares de direitos; a Declaração Francesa não considerava as mulheres em sua individualidade; nestas sociedades, o voto era censitário, e tanto os pobres quanto os analfabetos não podiam participar da vida política (TOSI, 2005, p.113). Por outro lado, para Marx, o processo de universalização dos direitos liberais que se constituiu a partir 
da expansão europeia sobre o resto do mundo, seria, na realidade, a história da criação de um mercado mundial ${ }^{4}$, e com ela iniciou-se um grande movimento de colonização e exploração dos extra-europeus, para os quais os direitos não eram uma realidade, admitindo-se, inclusive, a escravidão.

Outro ponto a ser destacado na crítica marxista aos direitos liberais diz respeito a separação entre o ser humano e o cidadão, presente de maneira clara em A Questão Judaica, de 1843. Para Marx, a passagem do feudalismo para o capitalismo dividiu o espaço social em um domínio político (Estado), e um domínio privado - esfera de interesses particulares - que chamou de sociedade civil, contudo, a emancipação política alcançada que libertou os homens do antigo regime não foi suficiente para produzir uma emancipação humana (ou emancipação real), pois reduziu o homem a um duplo aprisionamento: primeiro, como membro de uma sociedade civil burguesa e individualista; e segundo, como cidadão abstrato de um Estado (ATIENZA, 1982, p.46). É o que se verifica nas palavras de Marx (1989, p.10) ao afirmar que "os limites da emancipação política surgem imediatamente no fato de o Estado se poder libertar de um constrangimento, sem que o homem se encontre realmente liberto".

Essa distinção entre direitos do homem e direitos do cidadão, ou em outras palavras, entre sociedade civil e Estado, que desprende-se das declarações de direitos liberais, seria responsável pela alienação humana pois, considerando que o homem egoísta e membro da sociedade burguesa seria a base material do Estado político, ou seja, do homem enquanto cidadão, os direitos do cidadão se põem a serviço dos direitos do homem, e assim, a vida política se transforma num meio para a consecução dos fins da sociedade burguesa. Explica o filósofo alemão que "ao emancipar-se politicamente, o homem emancipa-se de modo obliquo, por meio de um intermediário, por mais necessário que tal intermediário seja" (MARX, 1989, p.11).

Ao abolir formalmente as diferenças materiais entre os homens, através da lei, da distribuição de direitos abstratos, o Estado liberal acaba por pressupor a existência da diferenciação humana, pois relega à sociedade civil e à propriedade privada o tratamento das questões à sua maneira. Como explica Douzinas (2009, p. 170), perceba-se que as dimensões do universal e do particular permanecem assim em oposição, pois, se por um lado o Estado se metaforizava na tarefa de servir ao homem universal, por outro lado, promovia os interesses privados da classe burguesa , de maneira que os direitos distribuídos conforme a tradição liberal davam suporte a uma ordem social desumana. A figura do Estado, portanto, estaria

4 "Na história existente até o momento, é certamente um fato empírico que os indivíduos singulares, com a transformação da atividade em atividade histórico-mundial, tornam-se cada vez mais submetidos a um poder que lhes é estranho...um poder que se tornou cada vez mais maciço e se revela, em última instância, como mercado mundial" (MARX; ENGELS, 1982, p.53-54). 
longe de ser uma figura neutra, resultado da livre associação dos indivíduos como defendeu Locke no seu Dois Tratados sobre o Governo.

Merecem menção, ainda, os argumentos marxistas no que diz respeito à noção de liberdade no pensamento liberal. Enquanto no liberalismo liberdade significa a faculdade de empreender tudo aquilo conforme os próprios desejos sem prejudicar as liberdades alheias, para Marx, o direito à liberdade não se baseia na união do homem com o homem, mas, pelo contrário, na separação do homem em relação a seu semelhante. A liberdade é o direito a esta dissociação, o direito do indivíduo delimitado, limitado a si mesmo. È justamente a liberdade individual que "leva cada homem a ver nos outros, não a realização, mas a limitação da sua própria liberdade" (MARX, 1989, p.24).

Tem-se então uma crítica severa ao caráter negativo da liberdade liberal, que se apresenta não só em função do Estado, mas sobretudo na relação homem/homem, que conforme explica Douzinas (2009, p.171), é responsável pela construção de uma sociedade de mônadas isoladas que se veem como uma ameaça para a consecução de seus fins particulares. Nesse sentido o valor social máximo não é o bem comum, mas a segurança, o princípio do policiamento, que garante o egoísmo burguês. Afirmou Marx (1989, p.26) que a segurança consiste no conceito supremo da sociedade burguesa, segundo o qual "toda a sociedade somente existe para garantir a cada um de seus membros a conservação de sua pessoa, de seus direitos e de sua propriedade."

Não há, portanto, uma oposição ontológica de Marx aos direitos, nem tampouco à liberdade, nem à emancipação política, o que se revela da crítica marxista é o caráter idealista, abstrato e irrealizável dos direitos liberais, que se contrapõem assim à dimensão material e histórica de uma sociedade de indivíduos egoístas, regidas pela propriedade privada, pela concentração de riqueza e pela competição. A cidadania liberal seria assim apenas o avanço possível dentro de uma ordem prédeterminada.

A emancipação política representa, sem dúvida, um grande progresso. Não constitui, porém, a forma final de emancipação humana, antes é a forma final de emancipação humana dentro da ordem mundana até agora existente (MARX, 1989, p.15).

Marx defendeu o desenvolvimento livre das individualidades, que só seria possível numa sociedade de indivíduos não concorrentes, mas associados, de maneira que a crítica marxista aos direitos não se constituiu numa crítica de conteúdo, mas de forma, pois que os direitos deveriam ser considerados "em termos das determinações concretas a que estão sujeitos os indivíduos", pois, de outra maneira, se põem como instrumentos de parcialidade e exploração (MESZAROS, 2008, p.161). 
Em Critica ao Programa de Gotha, de 1875, Marx chama atenção para a necessidade de um direito desigual - e por isso mesmo não abstrato - diferente da forma jurídica liberal burguesa, ao afirmar que o direito em sua natureza consiste na aplicação de uma medida igual para indivíduos desiguais, e assim, a tarefa de livrarse dos inconvenientes do direito pressupõe a construção de um direito desigual (MARX, 2012, p.7). Daí que a cidadania marxista não se identifica com a ideia do direito a ter direitos, mas sim, do direito a ter o direito adequado à sua realidade substancial.

\section{CONCLUSÃO}

A descoberta de uma ordem existencial antropologicamente mutável em oposição à realidade pré-determinada por forças transcendentais representou um dos momentos mais significativos da história humana, representou, de fato, a passagem do homem objetivo para o homem sujeito, racionalmente identificado e moralmente distinto. Sem embargo, a ruptura operada pela modernidade instaura um conjunto de ideais que viriam a justificar definitivamente a preeminência do homem na escala dos seres.

Essa ruptura deu-se, em muito, devido aos contornos que a nova forma de administração do poder - o Estado - viria a apresentar, a começar pelas justificativas de sua própria existência, qual seja, a avença das liberdades humanas em favor da segurança legalista dessas mesmas liberdades. Eis o problema, a forma.

A forma escolhida para a afirmação da nova ordem renegou ao esquecimento a tradição política dos gregos, e assumiu o caráter puramente legal dos romanos, trazendo na bagagem sua essência inseparável, a propriedade privada. Assim, o homem pertencente ao Estado, o cidadão, deixou de ser aquele que estabelecia relações ativas no espaço público, para se tornar aquele que, titular de propriedades, herdou um rol de direitos daí decorrentes.

Se por um lado o modelo liberal de reconhecimento e ampliação da cidadania a partir da distribuição de direitos, tal como consagrado no bojo das Declarações do século XVIII, foi importante na medida em que pretendeu - ao menos em discurso - um caráter universalista do valor do homem, por outro, esse mesmo modelo foi responsável pela instrumentalização daqueles homens que, no plano concreto, material, substancial, não abstrato, se distanciavam do padrão masculino, europeu, branco e burguês, transformados em meros meios para a consecução dos fins almejados pelo novo sistema econômico que se apresentava. 
A partir de uma análise histórica e dialética, é possível identificar que a cidadania liberal não foi suficiente para promover um real desenvolvimento das potencialidades humanas, uma vez que seu pressuposto individualista - o meu direito a ter meus direitos - alimentou a mútua concorrência, e consequentemente, a separação entre cidadãos (os que realmente têm direitos), e homens abstratos (os que possuem direitos apenas quando formalmente considerados).

Considerando o estágio atual de mundialização da cidadania liberal, e as mutações através das quais ela vem se mantendo intacta - tais como o surgimento do direito ao desenvolvimento e sua pretensa harmonia entre crescimento econômico e igualdade social; ou ainda, a adição de novas dimensões como a cultural e a ambiental aos tradicionais direitos civis, políticos e sociais - é quase inimaginável vislumbrar a construção de uma cidadania para a emancipação humana, como defendera Marx, a curto, médio, ou longo prazo. Porém, em sendo a realidade antropologicamente mutável, e partindo do reconhecimento de que uma proposta alternativa de cidadania se impõe como necessária diante das limitações da cidadania liberal, que se deixe à história, mais uma vez, a missão de provar que estamos enganados.

\section{REFERENCIAS}

ADORNO, Theodor W.; HORKHEIMER, Max. Dialética do Esclarecimento. Rio de Janeiro: Zahar, 2006.

ATIENZA, Manuel. Marx y los Derechos Humanos. Madrid: Mezquita, 1982.

BERLIN, Isaiah. Quatro ensaios sobre a liberdade. Brasília: Editora Universitária de Brasília, 1981.

BOBBIO, Norberto. A era dos direitos. Rio de Janeiro: Campos Elsevier, 2004.

COMPARATO, Fábio Konder. A nova cidadania. São Paulo: Lua Nova, 1993.

DOUZINAS, Costas. O fim dos direitos humanos. São Leopoldo: UNISINOS, 2009.

HAYEK, Friedrich August. Os princípios de uma ordem social liberal. In: CRESPIGNY, Anthony; CRONIN, Jeremy. Ideologias políticas. Brasília: Editora Universidade de Brasília, 1981. p. 47-63

HOBBES, Thomas. Leviatã. São Paulo: Martin Claret, 2006. (Coleção Obra Prima de Cada Autor)

HORKHEIMER, Max. Crítica de la razon instrumental. Buenos Aires: Editorial Sur, 1973.

Eclipse da Razão. São Paulo: Centauro, 2007.

KOSÍK, Karel. Dialética do concreto. São Paulo: Paz e Terra, 2011.

LEFEBVRE, Henri. Lógica Formal e Lógica Dialética. 5a ed. Rio de Janeiro: Civilização Brasileira, 1991.

LOCKE, John. Segundo tratado sobre o governo. São Paulo: Martin Claret, 2006.

MARSHALL, T. H. Cidadania, classe social e status. Rio de Janeiro: Zahar, 1967.

MARX, Karl, Crítica ao Programa de Gotha. São Paulo: Boitempo, 2012. 
A questão judaica. Covilhã: Lusosofia Press, 1989.

Manuscritos econômico: filosóficos. São Paulo: Boitempo, 2004.

; ENGELS, Friedrich. A ideologia alemã. 3 ed. São Paulo: Ciências Humanas, 1982.

MESZAROS, István. Filosofia, Ideologia e Ciência Social. São Paulo: Boitempo, 2008.

MILL, John Stuart. Sobre a liberdade. Lisboa: Edições 70, 2006.

PINSKY, Jaime e Carla Bassanezi. História da Cidadania. São Paulo: Contexto, 2008.

PLATÃO. A República. Tradução de Pietro Nassetti. São Paulo: Martin Claret, 2009.

POCOCK, J. G. A. The ideal of citizenship since classical times. In: BEINER, Ronald. Theorizing Citzenship. New York: State University of New York Press, 1995.p.29-52

ROUSSEAU, J.J. Discurso sobre a economia política e contrato social. Petrópolis: Vozes, 1996.

SANTOS, Boaventura de Sousa. Porque é tão difícil construir uma teoria crítica? Revista Crítica de Ciências Sociais da Faculdade de Economia da Universidade de Coimbra. n. 54, jun./1999. p. 197-215. Disponível em: < http://www.boaventuradesousasantos.pt/media/pdfs/Porque_e_tao_dificil_construir_teoria_critica_ RCCS54.PDF.> Acesso em: 15 de novembro de 2012.

TOSI, Giuseppe. Direitos Humanos: história, teoria e prática. João Pessoa: Editora UFPB, 2005.

\section{Mazukyevicz Ramon S. N. Silva}

mazukyevicz@hotmail.com

Doutorando e Mestre em Direitos Humanos pela Universidade Federal da Paraíba. Especialista em Segurança Pública e Direitos Humanos pelo Núcleo de Cidadania e Direitos Humanos da UFPB. Consultor do Instituto Nacional de Estudos e Pesquisas Educacionais - INEP na área de educação em prisões. Professor de Teoria da Argumentação Jurídica, Direitos Humanos e Ciências Criminais. 